\title{
Uso do TSH Recombinante no Câncer Diferenciado de Tireóide
}

\section{Caro Editor,}

ostaria de parabenizar o Editor-Chefe dos Arquivos Brasileiros Ide Endocrinologia \& Metabologia pela Edição Especial "Câncer de Tireóide", ABE\&M, Julho de 2007, 51/5. Trata-se de um volume para ser guardado por todos envolvidos no estudo do Câncer de Tireóide, pelas excelentes contribuições internacionais e nacionais, extremamente atualizadas, envolvendo os diversos aspectos moleculares, fisiopatológicos e de tratamento das diversas formas de Câncer de Tireóide. Nessa edição é apresentado o Consenso Brasileiro de Nódulos de Tireóide e Câncer Diferenciado de Tireóide (1) por um grupo representando o Departamento de Tireóide da SBEM (Ana Luiza Maia, Laura S. Ward, Gisah A. Carvalho, Hans Graf, Rui M.B. Maciel, Léa M. Zanini Maciel, Pedro W. Rosário e Mário Vaisman). O importante estímulo das Dras. Denise Carvalho (então Presidente do Departamento de Tireóide) e Edna Kimura foi essencial para que esse Consenso pudesse ser efetivado. Neste momento, os Consensos Brasileiros vão poder contribuir para as definições dos Consensos da LATS (Sociedade Latino-Americana de Tireóide) sobre Nódulos e Câncer de Tireóide. Essa Edição Especial, além de contar com as participações dos colegas estrangeiros James A. Fagin, Manuel Sobrinho-Simões, Pilar Santisteban, Alfredo Fusco, Massimo Santoro, Sonia Moretti, Shunichi Yamashita, Richard T. Kloos, Bruce Robinson, Guillermo Juvenal, Mario Pisarev, Maria A. DaGrosa e Guilermo Juvenal, teve a importante contribuição de muitos tireoidologistas básicos e clínicos, cirurgiões, endócrino-pediatras e imaginologistas brasileiros, fazendo com que o resultado final fosse muito mais um pequeno tratado sobre Câncer de Tireóide. O tópico seguimento do Câncer Diferenciado de Tireóide (CDT) foi enriquecido com o manuscrito "O ensaio da Tireoglobulina com melhor sensibilidade funcional enquanto os pacientes tomam L-T4 substituirá a Tireoglobulina estimulada pelo TSH no seguimento dos pacientes com Câncer diferenciado de Tireóide?” (2), no qual se discute o papel potencial da dosagem da Tireoglobulina (TG) mais sensível no seguimento do CDT, dispensando o estímulo endógeno ou exógeno do TSH. Essa edição especial também abordou o seguimento dos pacientes com CDT com o manuscrito "Uso do TSH Humano Recombinante no Câncer Diferenciado de Tireóide" (3), onde se discute o uso do TSH Recombinante Humano (TSHrh) na Ablação de Remanescentes Tireoideanos (ART) no CDT, no seguimento do CDT e no uso potencial do TSHrh no tratamento do CDT Recorrente ou Metastático. Desta forma, temos na mesma edição a oportunidade de uma análise crítica das diversas abordagens no seguimento do CDT. A experiência com o uso do TSHrh na ART tem mostrado resultados idênticos à ART na vigência de hipotireoidismo, com uma melhor relação custo/benefício, em função da melhor qualidade de vida e menor perda de dias de trabalho do paciente (4). Para que as diferentes estratégias no seguimento do CDT possam ser utilizadas nas instituições públicas brasileiras e pelos diversos planos de saúde, a questão

\section{carta ao editor}

\section{Hans GraF}

Professor de Endocrinologia da UFPR, Curitiba, PR.

Recebido em 18/09/07

Aceito em 20/09/07 
do custo necessita ser muito bem analisada. Para contribuir neste particular, gostaria de fazer um pequeno reparo sobre o preço mencionado do TSHrh (2). Temos encontrado atualmente menor dificuldade na aceitação da prescrição do TSHrh (3), quando o produto está bem indicado, pelos planos de saúde, sendo provavelmente uma das razões a redução do preço em $54 \%$ do mesmo. Embora existam diferenças no preço do medicamento entre os estados, o valor gira em torno de $\mathrm{R} \$ 3.900,00$. A maior acessibilidade do produto para os pacientes que podem potencialmente se beneficiar do mesmo deveria, de forma ideal, ser estendida para os pacientes usuários do nosso sistema de saúde.

Atenciosamente, Hans Graf MD, PhD

\section{REFERÊNCIAS}

1. Maia AL, Ward LS, Carvalho GA, Maciel RMB, Maciel LMZ, Rosário PW, et al. Nódulos de Tireóide e Câncer Diferenciado de Tireóide: Consenso Brasileiro. Arq Bras Endocrinol Metab 2007;51/5:867-93.

2. Maciel RMB. O ensaio da tiroglobulina com melhor sensibilidade funcional enquanto os paciente toma L-T4 substituirá a tireoglobulina estimulada pelo TSH no seguimento dos pacientes com câncer diferenciado de tireóide? Arq Bras Endocrinol Metab 2007;51/5:862-6.

3. Graf H, Paz-Filho G. Uso do TSH humano recombinante no câncer diferenciado de tireóide. Arq Bras Endocrinol Metab 2007;51/5:806-12.

4. Luster M, Lippi F, Jarzab B, Perros P, Lassmann M, Reiners C, et al. rhTSH-aided radioiodine ablation and treatment of differentiated thyroid carcinoma: a comprehensive review. Endocr Relat Cancer 2005;12:49-64.

Endereço para correspondência:

Hans Graf

Rua Solimões 1184

80810-070 Curitiba, PR 